\title{
The thermoanalytical, infrared and pyrolysis-gas chromatography-mass spectrometric sifting of poly (methyl methacrylate) in the presence of phosphorus tribromide
}

\author{
Muhammad Arshad $^{1^{*}}$, Khalid Masud ${ }^{2}$, Muhammad Arif ${ }^{3}$, Saeed-ur-Rehman ${ }^{4}$, \\ Jamshed H. Zaidi ${ }^{1}$, Muhammad Arif ${ }^{1}$, Aamer Saeed ${ }^{5}$, Tariq Yasin ${ }^{6}$ \\ ${ }^{1}$ Chemistry Division, Directorate of Science, PINSTECH, Islamabad, Pakistan; marshads53@yahoo.com.sg \\ ${ }^{2}$ New Laboratories Pinstech, Islamabad, Pakistan \\ ${ }^{3}$ Department of Chemistry, Bahauddin Zakariya University, Multan, Pakistan \\ ${ }^{4}$ Institute of Chemical Sciences, University of Peshawar, Peshawar, Pakistan \\ ${ }^{5}$ Department of Chemistry, Quaid-i-Azam University, Islamabad, Pakistan \\ ${ }^{6}$ DCME, Pakistan Institute of Engineering \& Applied Sciences, Islamabad, Pakistan
}

Received 23 December 2009; revised 25 January 2010; accepted 29 January 2010.

\begin{abstract}
The behaviour of poly(methyl methacrylate) was examined in the presence of phosphorus tribromide $\left(\mathrm{PBr}_{3}\right)$ with varying concentrations. Films were cast from common solvent and subjected to TG, DTA, DTG, IR and Py-GC-MS for evaluating the degradation routes. Despite early decomposition of the blends, certain temperature zones were identified for stabilization of the system. New products were found and mechanisms of their formation were proposed. Pyrolysis of the blends was also carried out at different temperatures to ascertain the nature of interaction between the constituents of the system.
\end{abstract}

Keywords: PMMA; $\mathrm{PBr}_{3}$; Thermoanalytical Study; IR Spectroscopy; GC-MS Investigation

\section{INTRODUCTION}

The thermal degradation and flammability characteristics of poly (methyl methacrylate) chemically modified with silicon-containing groups, functionalized by phosphorus-containing groups and also neat poly(methyl methacrylate) with a number of additives have been reported by several researchers [1-12].

Poly (methyl methacrylate) is widely used and studied poly alkyl methacrylate thermoplastic polymer, but it is highly flammable owing to the ease with which it degrades thermally (depolymerise), releasing large quantities of highly flammable volatile, monomeric and oli- gomeric frangments. Thermal decomposition characteristics of PMMA are well-understood $[2,9,10,13,14]$ and a lot of research work is underway to improve its flammability as well as other features by additive-route technique.

Our interest in the thermal behaviour of polymeric/ copolymeric systems and these systems in combination with additives (organometallics) has resulted in a number of publications [15-21]. It was observed with overwhelming evidence that polymers/ copolymers showed markedly different thermal behaviour when heated even in the presence of minor amounts of additives. The interaction between the constituents was chemical as well as physical. The products of degradation were identified as either completely different (new ones) or if same, exhibited variation in amounts when this feature of the neat and blended systems was compared. Physical nature of interaction was noticed due to the sublimation of additives in addition to the heat- sinking property of stable residues from the degradation of additives. The shifting of $\mathrm{T}_{\mathrm{i}}$ (temperature corresponding to the first weight-loss), $\mathrm{T}_{50}$ (temperature which designates the $50 \%$ weight-loss of the system) and $\mathrm{T}_{\max }$ (temperature which gives the maximum weight-loss) clearly indicates the effects of additives on the degradation of polymers/copolymers. Recently, our research activities have seen a shift in the nature of additives, i.e., from organometallics, we have started introducing purely inorganic compounds in polymers/copolymers of commercial importance [22,23]. This change in approach is based on the fact that the degradation of organometallics also results in the production of those species which are themselves flammable, whereas our aim is to modify the degradation mechanism in such a way as not only to increase the 
temperature of degradation but also to seek the formation of non-flammable or less flammable degradation products.

This paper is concerned with the influence of phosphorus tribromide - a non-metal halide - on the PMMA for the course of degradation with the aim to establish possible chemical interaction between the components by using different ratios of polymer and additive. Emphasis is laid on the mechanism of the observed effects, in particular, on the formation and identification of degradation products.

\section{EXPERIMENTAL}

\subsection{Chemicals}

All the reagents and solvents obtained from standard source suppliers (E. Merck) were of analytical grade. The monomer, methyl methacrylate, was freed from inhibitor (hydroquinone) by washing with aqueous 5\% sodium hydroxide followed by de-ionised water until neutral and then it was dried over anhydrous calcium chloride for 24 hours [24]. It was distilled under reduced pressure prior to use, only middle portion was chosen for polymerization. 2, 2'-azobisisobutyronitrile (AIBN) was selected as radical initiator for polymerization and was purified by re-crystallizing from absolute ethanol. The crystals obtained were dried under vacuum and kept in refrigerator (black paper wrapped around bottle). Phosphorus tribromide was prepared by the standard procedure [25]. All solvents were distilled by standard literature procedures before use.

\subsection{Preparation of Poly (Methyl Methacrylate)}

The homopolymer was synthesized by free radical polymerization by the reported procedure [26]. The purified monomer was de-aerated and vacuum-distilled into the calibrated dilatometer containing sufficient amount of 2, 2'-azobisisobutyronitrile initiator to give $0.7 \% \mathrm{w} / \mathrm{v}$ in the solution. The dilatometer was sealed under vacuum and polymerization was carried to $10 \%$ conversion at $60^{\circ} \mathrm{C}$ in hot water bath. The mixture was then added to $100 \mathrm{~mL}$ of toluene and the polymer was precipitated from 1 liter of methanol. The polymer was collected by filtration, vacuum dried, purified by reprecipitation (thrice) and finally dried in a vacuum oven at $50^{\circ} \mathrm{C}$ for 24 hours.

\subsection{Formulation of Blend for Analysis}

The blends with varying compositions of PMMA and phosphorus tribromide in the form of thin films were prepared by employing common solvent, i.e., acetone. The known amounts of polymer and additive were mixed separately in a sufficient quantity of acetone and were left overnight in closed Pyrex tubes to dissolve completely at ambient temperature. Both the solutions were mixed, shaken thoroughly, placed for 24 hours in dark place to mix completely and then poured into a well-cleaned transparent Pyrex dish. Complete evaporation of the solvent was effected at STP. The resultant film was transparent in the dish confirming the compatibility of the components of the pair studied.

\subsection{Procedure to Prepare Strip for Flammability Test}

For neat PMMA sample, the polymer was added to acetone and kept overnight to dissolve completely. The solution thus obtained, was poured into an aluminum mold with the dimensions, $1 \mathrm{~mm} \times 7 \mathrm{~mm} \times 150 \mathrm{~mm}$, the inside cavity of which was covered with high density polythene sheet. The mold was left for $48 \mathrm{hrs}$ in dark for complete dryness. For the blends, both polymer and additive in definite ratios were dissolved in acetone separately and set aside for $24 \mathrm{hrs}$. Individual solutions were then intermingled and placed in dark place for complete miscibility. This solution was then poured in the mold and allowed to dry for $48 \mathrm{hrs}$ in a thoroughly-cleaned dark place. The dry sample was removed and kept in desiccator for the required test.

\subsection{Physiochemical Methods}

Thermoanalytical (TG-DTA-DTG) curves were obtained using Netzsch Simultaneous Thermal Analyzer STA 429. All the measurements were carried out with samples having 30-60 mg initial mass. These were heated over the temperature range from ambient to $800^{\circ} \mathrm{C}$ in an inert atmosphere (nitrogen), using kaolin as reference material. The heating rate was $10^{\circ} \mathrm{C} \mathrm{min}^{-1}$.

Infrared (IR) spectra of polymer, additive and those of residues produced after heating the blends at various temperatures were recorded with Nicolet 6700 FT-IR spectrometer in the range $4000-400 \mathrm{~cm}^{-1}$.

The liquid chromatograph, Hitachi 655-A-11 with GPC software and integrator (D-2200 GPC) along with column GLA-100m (Gelko), was employed for molecular weight determination of polymer at room temperature. The detector system consisted of Hitachi 655-A UV variable wavelength monitor $(=254 \mathrm{~nm})$ and SE-51 (Shodex) refractive index detector. Polystyrene standards were used for calibration curves and HPLC grade tetrahydrofuran (Aldrich) was used as solvent. The molecular weight was found 120000 .

The samples were subjected to an Agilent 6890N type GC-MS coupled with 5973 inert MSD, by Agilent Analytical Instruments, Agilent Technologies, USA. Analysis of the products in acetone was performed with a DB-5MS column. The injection volume was $1 \mu \mathrm{L}$. The temperature program entailed an initial increase of temperature from $120-150^{\circ} \mathrm{C}$ at $10^{\circ} \mathrm{C} \mathrm{min}^{-1}$ and from $150-280^{\circ} \mathrm{C}$ at $15^{\circ} \mathrm{C} \mathrm{min}^{-1}$. The mass spectrometer was operated in the electron-impact (EI) mode at $70 \mathrm{eV}$. 
Horowitz and Metzger method [27] was used to calculate activation energy $\left(E_{0}\right)$ and order of reaction $(n)$ of polymer and its blends. A plot of $\ln \ln \mathrm{Wo} / \mathrm{Wt}$ (where Wo $=$ initial weight of material and $\mathrm{Wt}=$ weight of material at temperature $\mathrm{T})$ against $\theta(\theta=\mathrm{T}-\mathrm{Ts})$ resulted in a straight line. The activation energy was determined from its slope which was equal to $\mathrm{E}_{\mathrm{o}} / \mathrm{RTs}^{2}$ (where $\mathrm{R}=$ gas constant and $\mathrm{Ts}=$ temperature (from DTG peak) at which maximum weight-loss occurs). Order of reaction was calculated by using the relation between reaction order and concentration at maximum slope.

The horizontal burning test (HBT) of homopolymer and its blend was conducted in accordance with the ASTM standards $[28,29]$. The blend compositions given in Table 1 were prepared by mixing the polymer with additive in an aluminum mold with the specified dimensions. The specimen was held horizontally and a flame fuelled by natural gas was supplied to light one end of it. The time for the flame to reach from the first reference mark (25 $\mathrm{mm}$ from the end) to the second reference mark at $100 \mathrm{~mm}$ from the end, was measured. The results are reproduced in Figure 12.

\section{RESULTS AND DISCUSSION}

\subsection{Thermogravimetry, Derivative Thermogravimetry and Differential Thermal Analysis}

The thermal traces of additive (X), neat polymer (A) and blends, B1-B5, are shown in Figures 1-4, while thermoanalytical data are given in Table 1. The TG curve of neat phosphorus tribromide gives a single step weightloss. This additive begins to lose weight around $60^{\circ} \mathrm{C}$ and the whole process completes around $178^{\circ} \mathrm{C}$ (Figure 1). The first fifty per cent of the original weight requires heating of $105^{\circ} \mathrm{C}$ to disappear whereas the remaining

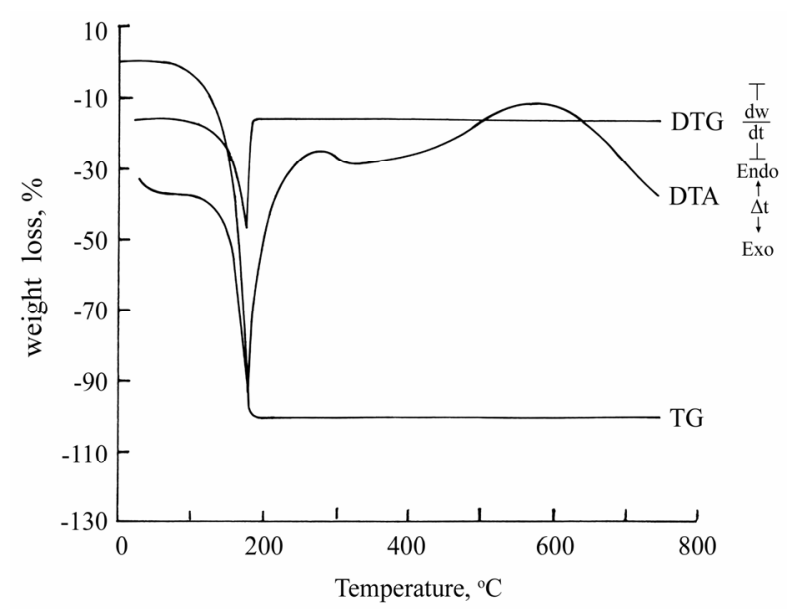

Figure 1. Thermal (TG-DTA-DTG) traces (dynamic nitrogen, heating rate $10^{\circ} \mathrm{C} / \mathrm{min}$ ) for phosphorus tribromide additive (X) in nitrogen atmosphere.

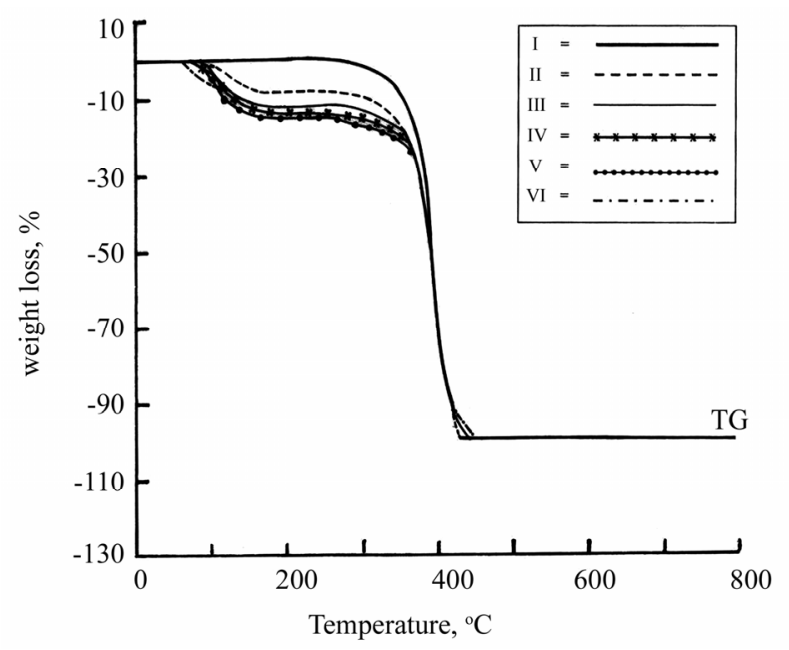

Figure 2. Thermogravimetry curves (dynamic nitrogen, heating rate $10^{\circ} \mathrm{C} / \mathrm{min}$ ) for PMMA-PBr 3 blends: (I) A, (II) B1, (III) B2, (IV) B3, (V) B4 and (VI) B5.

fifty per cent leaves the crucible within a temperature range of just $15^{\circ} \mathrm{C}$. A DTG peak is found at $178^{\circ} \mathrm{C}$ while DTA peak is noted at $176^{\circ} \mathrm{C}$. When $\mathrm{PBr}_{3}$ approaches its boiling point $\left(175^{\circ} \mathrm{C}\right)$, the weight-loss (evaporation) becomes brisk. This is also evident from the preceding observation. At the termination of weight- loss step, no residue is encountered.

This blend (PMMA 97.5\%: $\mathrm{PBr}_{3} 2.5 \%$-hereafter designated as $\mathrm{B} 1$ ) begins to degrade around $81^{\circ} \mathrm{C}$ and the first stage comes to an end at $169^{\circ} \mathrm{C}$ (Figure 2(II)). Nine per cent weight-loss is observed. The products evolved at this stage clearly indicate the interaction between the two components of the system (GC-MS results). The neat polymer exhibits $\mathrm{T}_{0}$ (temperature corresponding to the detection of first weight-loss) at $250^{\circ} \mathrm{C}$ (Figure 2(I)), whereas additive starts losing weight around $60^{\circ} \mathrm{C}$ when heated alone. This is another clue for interaction. From $169^{\circ} \mathrm{C}$ to $279^{\circ} \mathrm{C}$ the system remains intact thereby showing the stability of the intermediate. This intermediate is not pure PMMA as neat polymer commences to decompose around $250^{\circ} \mathrm{C}$. So it is believed that bonds between $\mathrm{PBr}_{3}$ and PMMA are formed which result in the stabilization of intermediate $\left(169-279^{\circ} \mathrm{C}\right)$. The second stage which terminates at $430^{\circ} \mathrm{C}$ accounts for $91 \%$ weight-loss. No residue is noticeable at the completion of degradation process. One DTG peak (Figure 3(II)) at $393^{\circ} \mathrm{C}$ and one DTA peak (Figure $4\left(\right.$ III)) at $408^{\circ} \mathrm{C}$ are noted for the final (second) stage. The sharp fall in TG traces for the second stage manifests the rupture of all types of bonds as the rising energy content cannot be resisted.

The second blend of this series B2 (PMMA 95\%: $\mathrm{PBr}_{3}$ $5 \%$ ) starts losing weight around $80^{\circ} \mathrm{C}$ and by the end of the first stage $\left(165^{\circ} \mathrm{C}\right)$, accounts for $12 \%$ weight-loss (Figure 2(III)). It is clear now that by increasing the 
Table 1. Comparative thermoanalytical data for $\mathrm{PMMA}(\mathrm{A}), \mathrm{PBr}_{3}(\mathrm{X})$ and blends, $\mathrm{B} 1-\mathrm{B} 5$.

\begin{tabular}{|c|c|c|c|c|c|c|c|c|c|c|}
\hline \multirow{2}{*}{$\begin{array}{c}\text { Blend composi- } \\
\text { tion }(\%) \\
\text { PMMA-PBr }\end{array}$} & \multirow{2}{*}{$\begin{array}{l}\text { Temperature } \\
\text { range, }{ }^{\circ} \mathrm{C}\end{array}$} & \multirow{2}{*}{ Stage } & \multirow{2}{*}{$\begin{array}{l}\text { Weight } \\
\text { loss, \% }\end{array}$} & \multicolumn{4}{|c|}{$\mathrm{TG},{ }^{\circ} \mathrm{C}$} & \multicolumn{2}{|c|}{ DTG, ${ }^{\circ} \mathrm{C}$} & \multirow{2}{*}{$\begin{array}{c}\text { DTA, }{ }^{\circ} \mathrm{C}, \\
\text { Thermal Effect }\end{array}$} \\
\hline & & & & $\mathrm{T}_{0}$ & $\mathrm{~T}_{25}$ & $\mathrm{~T}_{50}$ & $\mathrm{~T}_{100}$ & $\mathrm{I}$ & II & \\
\hline $\mathrm{A}(100-00)$ & $250-440$ & $\mathrm{I}$ & 100 & 250 & 378 & 390 & 440 & 396 & -- & 319 (Endo), 412 (Exo) \\
\hline B1 (97.5-2.5) & $\begin{array}{c}81-169 \\
279-430 \\
\end{array}$ & $\begin{array}{l}\text { I } \\
\text { II }\end{array}$ & $\begin{array}{c}9 \\
91 \\
\end{array}$ & 81 & 378 & 392 & 430 & 110 & 393 & $\begin{array}{l}130 \text { (Exo), } 350 \text { (Endo), } \\
408 \text { (Exo) }\end{array}$ \\
\hline B2 (95-5) & $\begin{array}{c}80-165 \\
262-440\end{array}$ & $\begin{array}{l}\text { I } \\
\text { II }\end{array}$ & $\begin{array}{l}12 \\
88\end{array}$ & 80 & 380 & 390 & 440 & 111 & 396 & $\begin{array}{l}120 \text { (Exo), } 363 \text { (Endo), } \\
407 \text { (Exo) }\end{array}$ \\
\hline B3 (92.5-7.5) & $\begin{array}{c}70-175 \\
280-445\end{array}$ & $\begin{array}{l}\text { I } \\
\text { II }\end{array}$ & $\begin{array}{l}14 \\
86\end{array}$ & 70 & 370 & 390 & 445 & 115 & 397 & $\begin{array}{l}118 \text { (Exo), } 350 \text { (Endo), } \\
404 \text { (Exo) }\end{array}$ \\
\hline B4 (90-10) & $\begin{array}{c}70-190 \\
260-441\end{array}$ & $\begin{array}{l}\text { I } \\
\text { II }\end{array}$ & $\begin{array}{l}16 \\
84\end{array}$ & 70 & 365 & 390 & 441 & 110 & 393 & $\begin{array}{l}124 \text { (Exo), } 365 \text { (Endo), } \\
406 \text { (Exo) }\end{array}$ \\
\hline B5 (87.5-12.5) & $\begin{array}{c}62-192 \\
243-448 \\
\end{array}$ & $\begin{array}{l}\text { I } \\
\text { II }\end{array}$ & $\begin{array}{l}11 \\
89 \\
\end{array}$ & 62 & 370 & 394 & 448 & 123 & 397 & $\begin{array}{l}136 \text { (Exo), } 365 \text { (Endo), } \\
415 \text { (Exo) }\end{array}$ \\
\hline $\mathrm{X}(00-100)$ & $60-178$ & I & 100 & 60 & 155 & 168 & 178 & 178 & -- & $176($ Exo) \\
\hline
\end{tabular}

Endo $=$ Endothermic, Exo $=$ Exothermic.

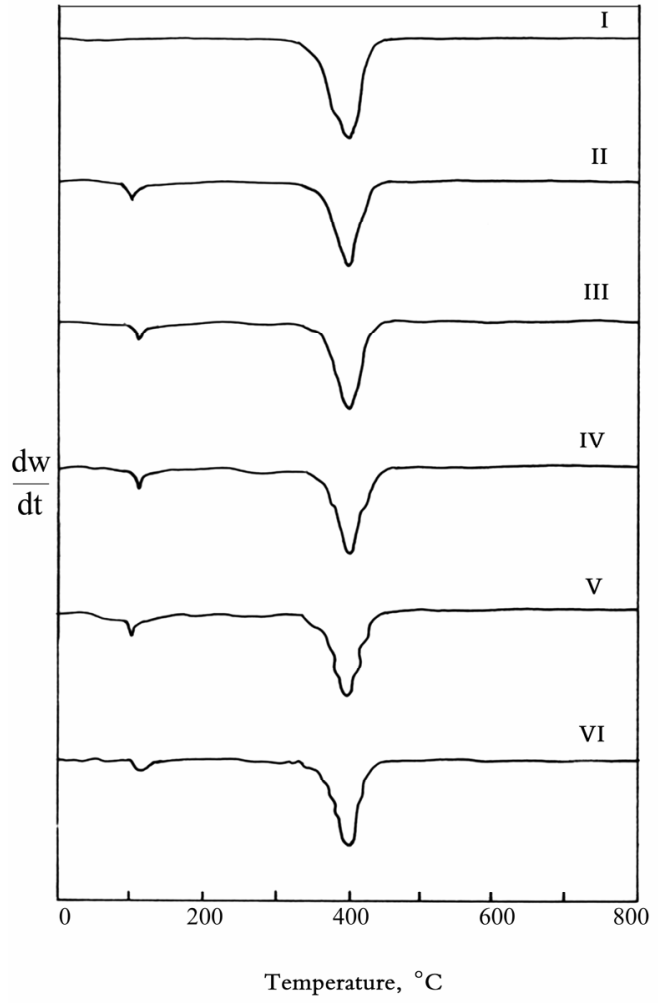

Figure 3. Derivative thermogravimetry curves (dynamic nitrogen, heating rate $10^{\circ} \mathrm{C} / \mathrm{min}$ ) for PMMA- $\mathrm{PBr}_{3}$ blends: (I) A, (II) B1, (III) B2, (IV) B3, (V) B4 and (VI) B5.

concentration of additive $\left(\mathrm{PBr}_{3}\right)$, the $\mathrm{T}_{0}$ does not show any change, however, the per cent weight-loss has increased. Same type of interaction is believed to have occurred for this blend as was observed for B1. The range of temperature for stable residue $\left(165-262^{\circ} \mathrm{C}\right)$ in this case exhibits a reduction when compared with the same range for the first member of this series (B1). It may be due to less number of bonds/links formed between

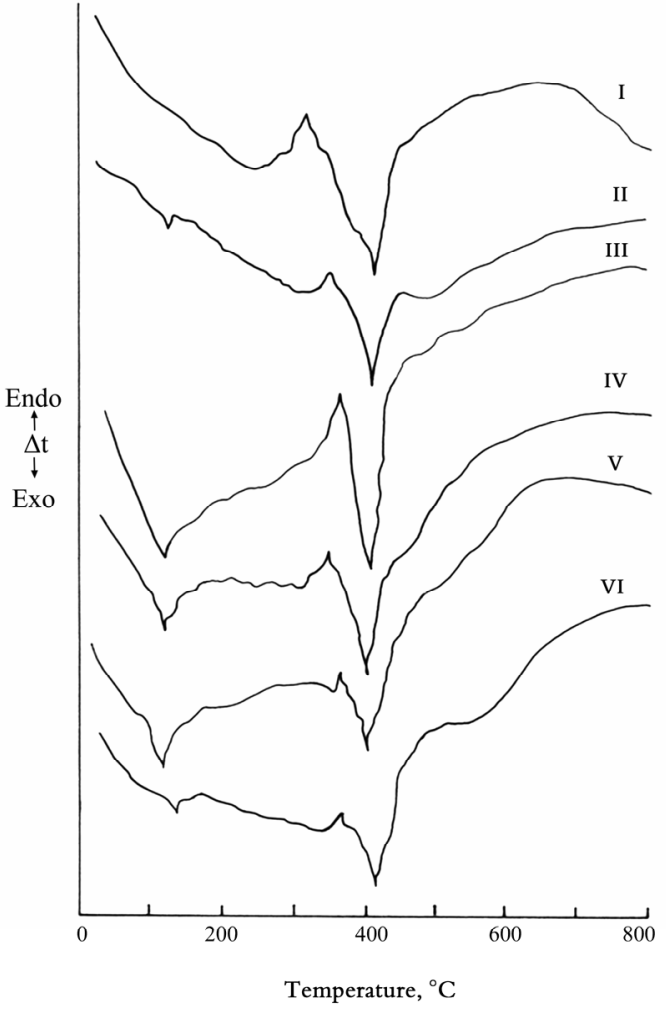

Figure 4. Differential thermal analysis curves (dynamic nitrogen, heating rate $10^{\circ} \mathrm{C} / \mathrm{min}$ ) for $\mathrm{PMMA} \mathrm{PBr}_{3}$ blends: (I) $\mathrm{A}$, (II) $\mathrm{B} 1$, (III) B2, (IV) B3, (V) B4 and (VI) B5.

the constituents of the system despite the presence of relatively higher concentration of additive. The last stage $\left(262-440^{\circ} \mathrm{C}\right)$ gives a weight-loss of $88 \%$. From $262^{\circ} \mathrm{C}$ to $360^{\circ} \mathrm{C}$, the weight-loss is only $7 \%$ which is attributed to the strength of bonds/interactions developed in the earlier part of the degradation between the components of the system resulting in the stable intermediate. For first stage, one DTG peak $\left(111^{\circ} \mathrm{C}\right)$ and one DTA peak $\left(120^{\circ} \mathrm{C}\right)$ 
appear. For second step, one DTG (Figure 3(III)) and two DTA (Figure 4(III)) peaks are noticed at $396^{\circ} \mathrm{C}$, $363^{\circ} \mathrm{C}$ and $407^{\circ} \mathrm{C}$, respectively. No residue is found at the termination of the degradation process.

B3 (PMMA 92.5\%: $\mathrm{PBr}_{3} 7.5 \%$ ) begins to degrade around $70^{\circ} \mathrm{C}$ and loses $14 \%$ of original weight in the first stage which terminates at $175^{\circ} \mathrm{C}$ (Figure 2(IV)). The intermediate formed at this stage is stable up to $280^{\circ} \mathrm{C}$ after which the pyrolysis again starts and the second step shows a weight-loss of $86 \%$ with no residue at the completion of the decomposition $\left(445^{\circ} \mathrm{C}\right)$. From $280^{\circ} \mathrm{C}$ to $338^{\circ} \mathrm{C}$, only $6 \%$ weight-loss is observed which is indicative of the toughness of bonds that developed during the early part of pyrolysis. One DTG (Figure 3(IV)) and one DTA (Figure 4(IV)) peak appear for first stage $\left(115\right.$ and $118^{\circ} \mathrm{C}$, respectively), however, for second stage one DTG and two DTA peaks at $397^{\circ} \mathrm{C}, 350^{\circ} \mathrm{C}$ and $404^{\circ} \mathrm{C}$, respectively, arise.

B4 (PMMA 90\%: $\mathrm{PBr}_{3}$ 10\%) shows a weight-loss of $16 \%$ for first stage. It commences to decompose around $70^{\circ} \mathrm{C}$ and stops losing weight around $190^{\circ} \mathrm{C}$ (Figure 2(V)). Single DTG (Figure 3(V)) and DTA (Figure 4(V)) peaks are found at $110^{\circ} \mathrm{C}$ and $124^{\circ} \mathrm{C}$, respectively. The intermediate withstands a temperature of $70^{\circ} \mathrm{C}$ (190$260^{\circ} \mathrm{C}$ ) before the inception of second stage of degradation. The second step comes to an end at $441{ }^{\circ} \mathrm{C}$ marking a weight-loss of $84 \%$. The first $6 \%$ weight-loss of second stage requires heating of $96^{\circ} \mathrm{C}$ which is due to the strong bonds/links produced in the early part of the degradation. One DTG and two DTA peaks are observed at 393,365 and $406^{\circ} \mathrm{C}$, respectively. No residue is noticeable at the completion of degradation process.

B5 (PMMA 87.5\%: $\mathrm{PBr}_{3}$ 12.5\%) commences its weightloss around $62^{\circ} \mathrm{C}$ for first stage which comes to an end at $192^{\circ} \mathrm{C}$ (Figure 2(VI)). One DTG and one DTA peak appear for this step at $123^{\circ} \mathrm{C}$ and $136^{\circ} \mathrm{C}$, respectively. Eleven per cent weight-loss is evident from TG traces (Figure 2(VI)). The intermediate that is stable up to $243^{\circ} \mathrm{C}$, starts decomposing as the temperature increases. The second stage terminates at $448^{\circ} \mathrm{C}$. One DTG (Figure 3(VI)) and two DTA (Figure 4(VI)) peaks are found at $397^{\circ} \mathrm{C}, 365^{\circ} \mathrm{C}$ and $415^{\circ} \mathrm{C}$, respectively. The first $8 \%$ weight-loss for the second step (out of $89 \%$ ) requires heating of $109^{\circ} \mathrm{C}$ (from 243 to $352^{\circ} \mathrm{C}$ ) whereas the remaining larger portion $(81 \%)$ leaves the scene for a heating of $96^{\circ} \mathrm{C}\left(352-448^{\circ} \mathrm{C}\right)$. This is basis of the types of bonds present in the intermediate. There was no residue at the end of pyrolysis of this blend.

The interaction is clear between the components of the system throughout the series, i.e., B1-B5. The nature of interaction seems to be same for all members of the series with effectiveness decreasing down the series. The percentage of degradation for first stage is higher than the total percentage of additive in the blends B1-B4. The molecular level mixing of the constituents favours the development of links between them which, in turn, in- fluences the degradation of both parts from the beginning. The evolution of new products (GC-MS results) in the early part of pyrolysis confirms the chemical interaction and mutual effect of the ingredients on each other's decomposition.

\subsection{Blend's Composition Effect on Thermal Behaviour}

Figure 5 shows the graph between temperature and weight $\%$ of additive. The results reveal a very clear trend of destabilization when $\mathrm{T}_{0}$ is considered. It is observed that as the percentage of additive in the blends is increased, a slight stabilization of $20^{\circ} \mathrm{C}$ is noted which may be attributed to the number of links which are developed between phosphorus and pendent oxygens of polymer per unit volume of additive. For $\mathrm{T}_{25}$ (temperature at which $25 \%$ weight-loss occurs), the trend in destabilization is not so different for blends when weight percentage of additive goes from 2.5 to 12.5 . This seems to be due to the less number of interactions, i.e., cumulative impact to lowers. At $\mathrm{T}_{50}$ (temperature at which 50\% weight-loss is observed), a very inappreciable stabilization is observed as energy content is too great to be resisted by the different types of interactions or bonds between additive and polymer irrespective of the weight percentage of additive. $\mathrm{T}_{100}$ (temperature for 100 weightloss) does not show much difference for polymer and blends which may be due to very high temperature region signifying the completion of decomposition process. In this zone, almost all kinds of bonds are prone to breakage.

\subsection{Activation Energy $\left(E_{o}\right)$ and Order of Reaction (n) Determination}

Table 2 presents the activation energy and order of reaction of thermal decomposition of polymer, additive and polymer-additive systems. A decreasing trend of activation energy is noticed with the increasing percentage of

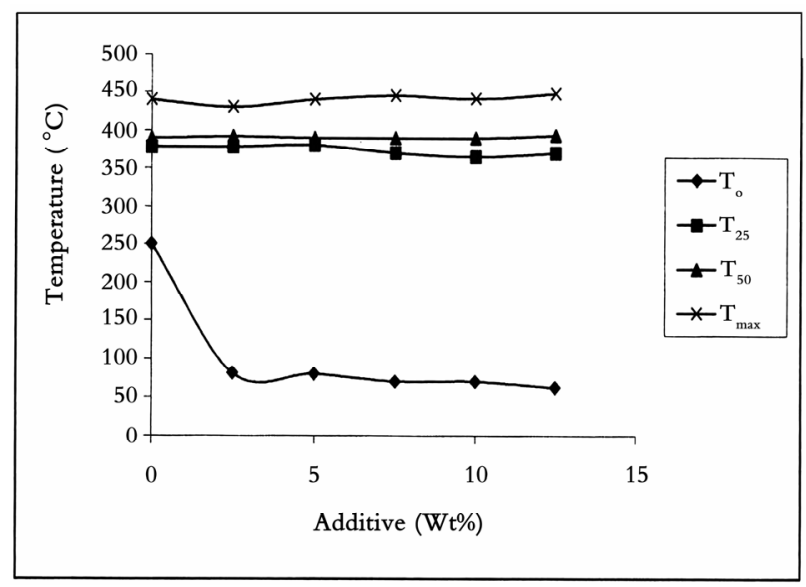

Figure 5. Effect of blend composition on $\mathrm{T}_{0}, \mathrm{~T}_{25}, \mathrm{~T}_{50}$ and $\mathrm{T}_{100}$ values of A and B1-B5 blends. 
Table 2. Activation energies and order of reaction for A, X and PMMA-additive blends.

\begin{tabular}{ccc}
\hline $\begin{array}{c}\text { Blend composition }(\%) \\
\text { PMMA-PBr }\end{array}$ & $\begin{array}{c}\mathrm{E}_{\mathrm{o}}^{*} \\
(\mathrm{KCal} / \mathrm{mol})\end{array}$ & $\begin{array}{c}\text { Order of reaction } \\
(\mathrm{n})\end{array}$ \\
\hline $\mathrm{A}$ & 138.9 & $3 / 2$ \\
$\mathrm{~B} 1$ & 43.68 & $1 / 2$ \\
$\mathrm{~B} 2$ & 42.17 & $1 / 2$ \\
$\mathrm{~B} 3$ & 40.29 & 1 \\
$\mathrm{~B} 4$ & 37.65 & 1 \\
$\mathrm{~B} 5$ & 38.03 & $3 / 2$ \\
$\mathrm{X}$ & 93.32 & 0 \\
\hline
\end{tabular}

$*=$ overall activation energy.

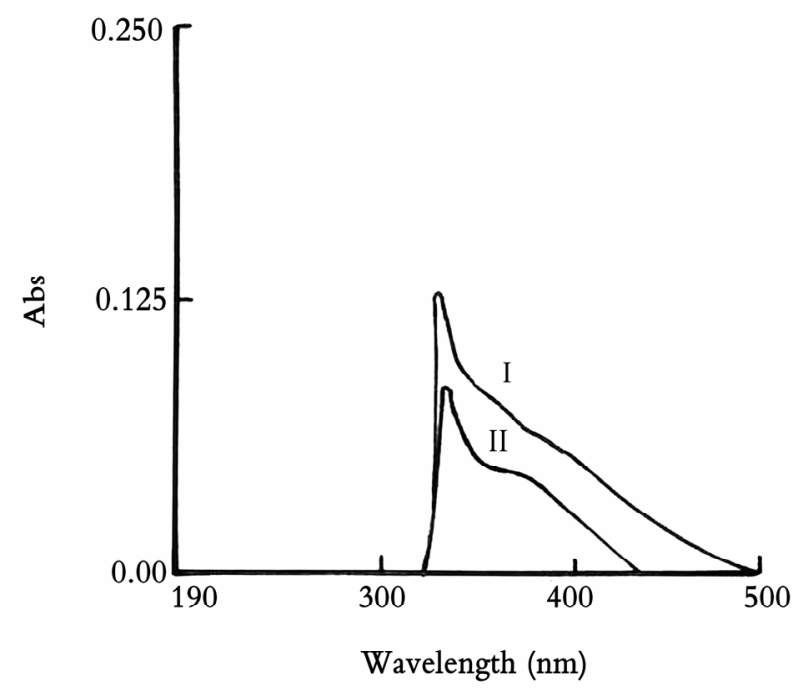

Figure 6. UV-spectra of X (I) and B4 (II) blend in acetone.

additive (2.5-12.5\%) in the blends. These results were computed from TG curves. It is believed that decrease in the activation energy is due to the destabilization of the blended system observed in the earlier part of pyrolysis keeping $T_{0}$ in view. The interaction at the outset of degradation between the components of blends triggers an early loss of weight which is attributed to the decreasing trend this parameter exhibits down the series $(\mathrm{B} 1 \rightarrow \mathrm{B} 5)$. The shifting of $\mathrm{T}_{0}$ to lower temperatures from $\mathrm{B} 1$ to $\mathrm{B} 5$ is quite evident in the current thermal investigation.

\subsection{UV Findings}

It is well-known fact that PMMA does not absorb in UV region. On the contrary, $\mathrm{PBr}_{3}$ gives a distinct peak at $325 \mathrm{~nm}$ (in acetone) whereas its blend with PMMA also absorbs in UV range (Figure 6). The shift in wavelength

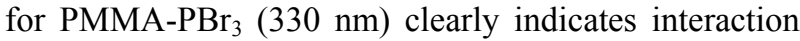
between the components of the system. This shift is attributed to the establishment of links between phosphorus of additive and carbonyl oxygen of polymer and bromines of additive and carbons of polymer backbone (main chain).

\subsection{IR Spectra}

Poly(methyl methacrylate) is a widely-studied polymer and its IR spectrum (Figure 7(I)) gives the characteristic peaks for the presence of ester linkages (1730-1735 $\left.\mathrm{cm}^{-1}\right)$. The absence of peaks in the region of 1630-1640 $\mathrm{cm}^{-1}$ confirms the formation of polymer. The stretchings attributed to $\mathrm{C}-\mathrm{H}$ bonds can be observed around 3000 $\mathrm{cm}^{-1}$.

The IR of $\mathrm{PBr}_{3}$ (Figure 7(II)) shows a broad band at $3362 \mathrm{~cm}^{-1}$ which is due to water absorption (all our endeavors to save $\mathrm{PBr}_{3}$ from taking moisture from surroundings failed as the humidity was high at the time of IR run). The remaining peaks (485, 476, 458, 442, 418, $407 \mathrm{~cm}^{-1}$ ) are assigned to $\mathrm{P}-\mathrm{Br}$ bond [30]. The IR peaks for blend (B4-PMMA 90\%:PBr 3 10\% - selected arbitrarily to represent the whole series) exhibit some interesting features (Figure 7(III)). "Free" $\mathrm{PBr}_{3}$ is either completely absent or if present, is only at trace levels. The absence of peaks around $3362 \mathrm{~cm}^{-1}(\mathrm{O}-\mathrm{H}$ stretching for water) overrules the presence of free $\mathrm{PBr}_{3}$. The shift observed for ester linkages of PMMA (IR peak at $1718 \mathrm{~cm}^{-1}$ ) and appearance of some sharp peaks at 1434 , $1386,1141 \mathrm{~cm}^{-1}$ suggest formation of a 'complex-type' arrangement involving carbonyl oxygen of PMMA pendent groups (either of the same chain or two different chains) and phosphorus of $\mathrm{PBr}_{3}$. The following structures are proposed.

Few more peaks at 1238, 667, 599, $564 \mathrm{~cm}^{-1}$ indicate that $\mathrm{Br}$ of $\mathrm{P}-\mathrm{Br}$ bond 'experiences' a pull from nearby carbons (backbone as well as ester carbons) [30-33]. For true $\mathrm{C}-\mathrm{Br}$ and $\mathrm{CH}_{3}-\mathrm{Br}$ bonds, the stretchings are found at $515-680$ and $\sim 1230 \mathrm{~cm}^{-1}$, respectively. This may result in the weakening of this bond ( $\mathrm{P}-\mathrm{Br})$ as $\mathrm{Br}$ 'moves' closer to the more electropositive carbon atoms. The results of GC-MS point towards these types of developments.

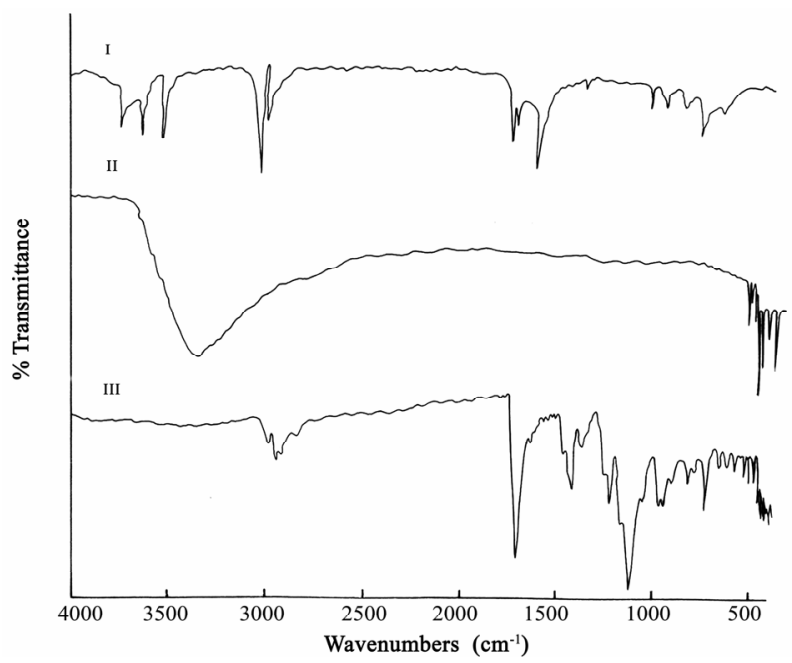

Figure 7. (I) Infrared spectra of PMMA; (II) Additive, $\mathrm{PBr}_{3}$; (III) Blend, B4, PMMA (90\%) + $\mathrm{PBr}_{3}(10 \%)$. 
<smiles>CCCCCCCCCCCC(C)(C)C(=O)OC</smiles>

and<smiles>COC(=O)C(C)(C)C(=O)OP(Br)(Br)(Br)OC(=O)C(C)(C)C</smiles>

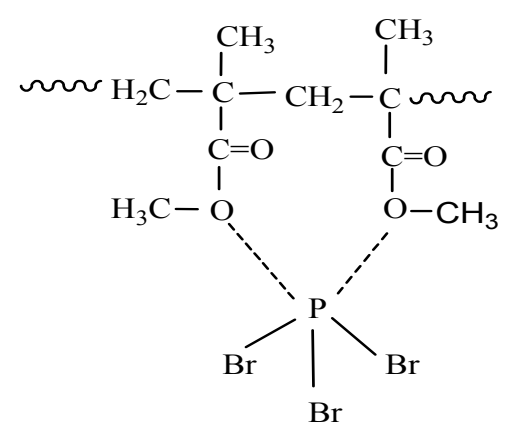

and<smiles>CCCC(C)(CC(C)(C)C(=O)OC)C(=O)OP(Br)(Br)(Br)P(Br)(Br)(Br)C(=O)OC</smiles>

and<smiles>CCCC(C)(CC(C)(CC)C(=O)OC)C(=O)OC</smiles>

\subsection{Pyrolysis-Gas Chromatography-Mass Spectrometry Behaviour}

The blend B4 (PMMA: $\mathrm{PBr}_{3}, 90 \%: 10 \%$ ) was heated to $250^{\circ} \mathrm{C}$ for a minute and after bringing the residue to room temperature, GC-MS was taken in acetone to check the nature of degrading blend around this temperature. B4 was selected arbitrarily to represent the present series. Since the blends show stability at or around $250^{\circ} \mathrm{C}$ (TG traces, Figure 2), the identification of products is expected to shed light on the interactions developed by the constituents of blends at this stage.

GC-MS of this blend (Figure 8) shows a number of peaks. The products identified clearly indicate the interaction between the components of the system from an early stage of degradation. The absence of $\mathrm{PBr}_{3}$ in the degradation products (it could not be found in a trap at $-196^{\circ} \mathrm{C}$ ) after heating $\mathrm{B} 4$ up to $250^{\circ} \mathrm{C}$ suggests its involvement with the pendent groups of the neat polymer or even with the backbone of the PMMA. However, the early weight-loss is attributed to the decomposition of some 'free' $\mathrm{PBr}_{3}$ which initiates the degradation of polymer. The formation of $\mathrm{Br}$ (free radicals) may result in the products of peaks at 1,3 , and 4. Peak number 7 , gives the bromine radicals replacing the methyls attached to the backbone carbons. The other peaks hint at either the contacts developed by one constituent $(\mathrm{P})$ of the additive $\left(\mathrm{PBr}_{3}\right)$ or both. The product at peak 8 provides the convincing clue for the stability of the system in the region unfolded by TG curves (Figure 2). The 


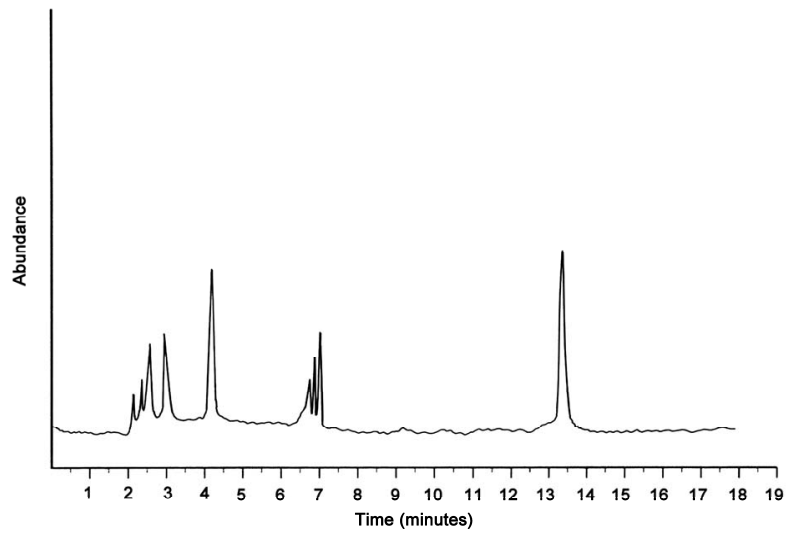

Figure 8. GC-MS results of blend, B4 (PMMA $(90 \%)+\mathrm{PBr}_{3}$ $(10 \%))$, heated at $250^{\circ} \mathrm{C}$.

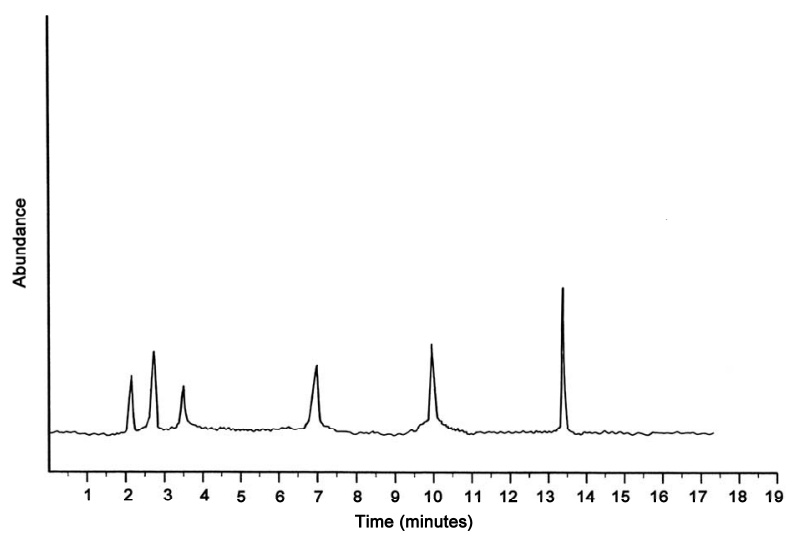

Figure 9. GC-MS results of blend, B4 (PMMA $(90 \%)+\mathrm{PBr}_{3}$ $(10 \%))$, heated at $300^{\circ} \mathrm{C}$.

interactions proposed as per IR studies (Figure 7) may be taken as proof now supported by GC-MS studies. The 'binding' of pendent groups of PMMA by phosphorus of additive may stop the degradation of polymer in certain temperature ranges furnishing stability to the system. The strength of the overall system lies in the 'engagement' of various chains by undegraded or partially degraded additive. The mechanism of the production of these compounds is presented in Schemes I-IV. Peak no. 9 provides a clue (which may also be regarded as the reason of stability of the system around this temperature, i.e., $250{ }^{\circ} \mathrm{C}$ ) whereby phosphorus is found as part of the backbone. It is worth-noting that phosphorus present in backbone of polymer is attached to carbon and hydrogen whereas bromine replaces either the $-\mathrm{OCH}_{3}$ of pendent group or $-\mathrm{CH}_{3}$ attached to backbone carbons. The formation of $-\mathrm{PH}_{2}$ and $-\mathrm{PH}$ - from $\mathrm{PBr}_{3}$ appears to have taken place along the degrading polymer. This also explains the "blockades" experienced by the degrading polymer [15,20,21].

The GC-MS taken after heating the blend (B4) up to $300^{\circ} \mathrm{C}$ is to get insight into the nature of products arisen, after the decomposition of stable intermediate (Figure 9).

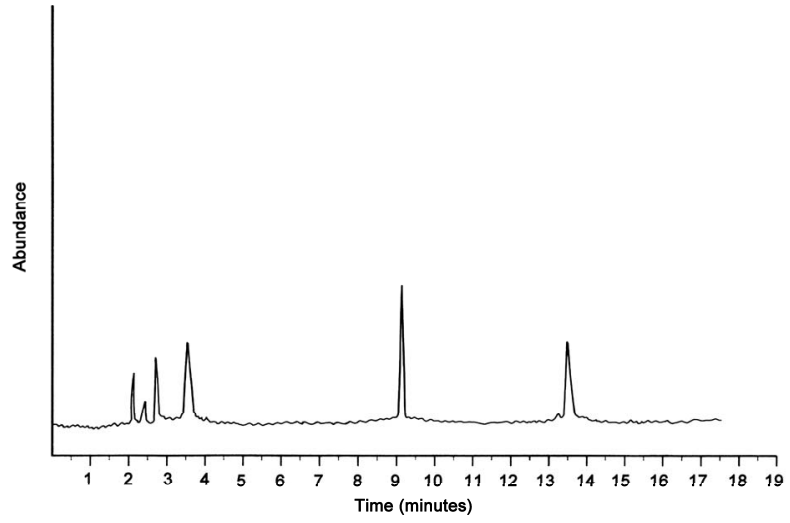

Figure 10. GC-MS results of blend B4, (PMMA $(90 \%)+\mathrm{PBr}_{3}$ $(10 \%))$, heated at $400^{\circ} \mathrm{C}$.

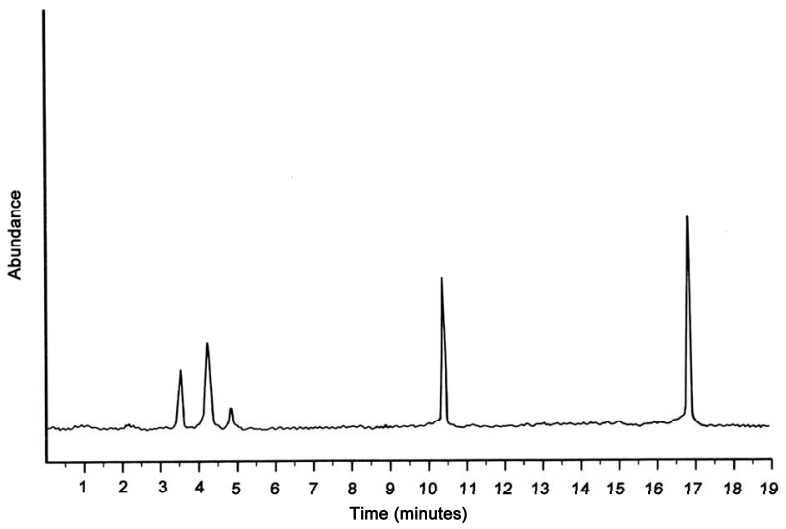

Figure 11. GC-MS results of blend B4 (PMMA $(90 \%)+\mathrm{PBr}_{3}$ $(10 \%))$, heated to boiling, cooled and mixed with acetone.

The product identified at peak number 5 does provide enough information about the stable intermediate. Phosphorus seems to be linked to two separate chains (Scheme V). Another product (peak no. 6) suggests as if $\mathrm{Br}$ (free radicals) blocks the depolymerisation of the chains (Scheme VI).

The products identified (Table 3 ) after heating the blend (B4) to $400^{\circ} \mathrm{C}$ also furnish evidence of the mechanism of degradation close to the completion of decomposition process (GC-MS, Figure 10). Despite inclusion of phosphorus in the chain (peak 3), replacement of some of the part of pendent group by phosphorus (peak 6) and presence of bromine (peak 6) at the end of few modified MMA units, the breaking of bonds takes place owing to the energy content of this temperature zone (at or around $400^{\circ} \mathrm{C}$ ). Unzipping of the chains cannot be hindered by phosphorus or bromine. Oligomers of neat MMA are absent which is another indication of interaction between the components of the system.

Another GC-MS (Figure 11) of this blend was recorded after heating to boiling for two minutes, cooling and then dissolving it in acetone. This was performed to check the overall behaviour of the blend subjecting it to 


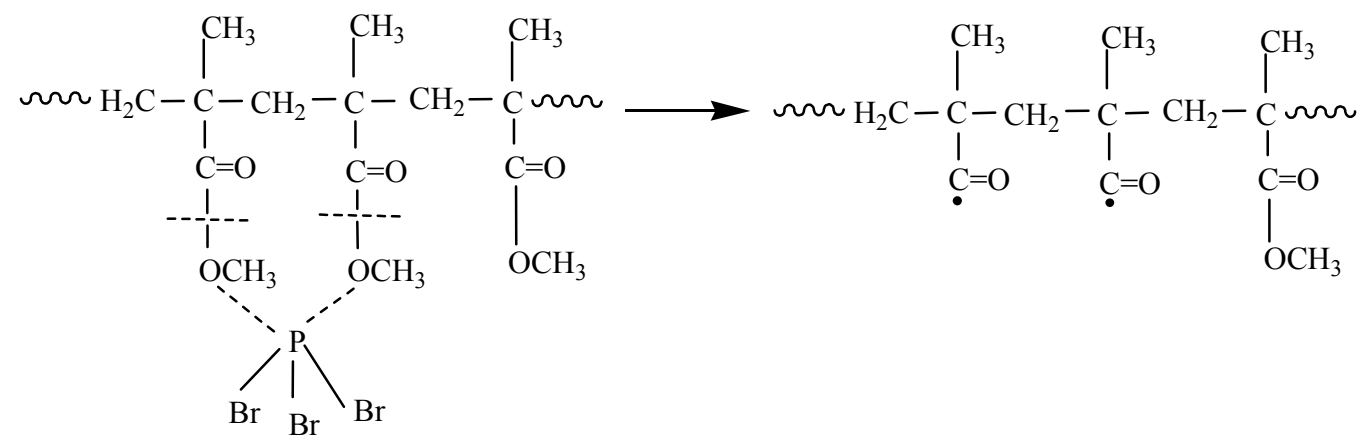<smiles>CCCCCC(C)(C=O)CC(C)(C=O)CC(C)(C[18O])C(=O)OC</smiles><smiles>[R]C(C)[C@@H](Br)[C@@H](C)CC(C)C=O</smiles>

Scheme I

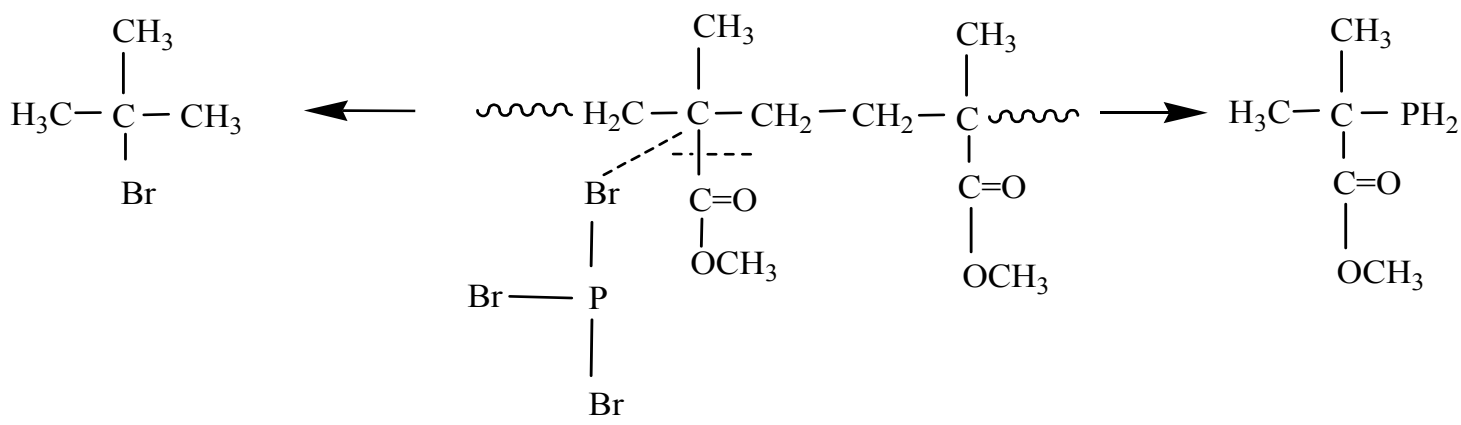<smiles>COC(=O)C=CBr</smiles>

Scheme II 

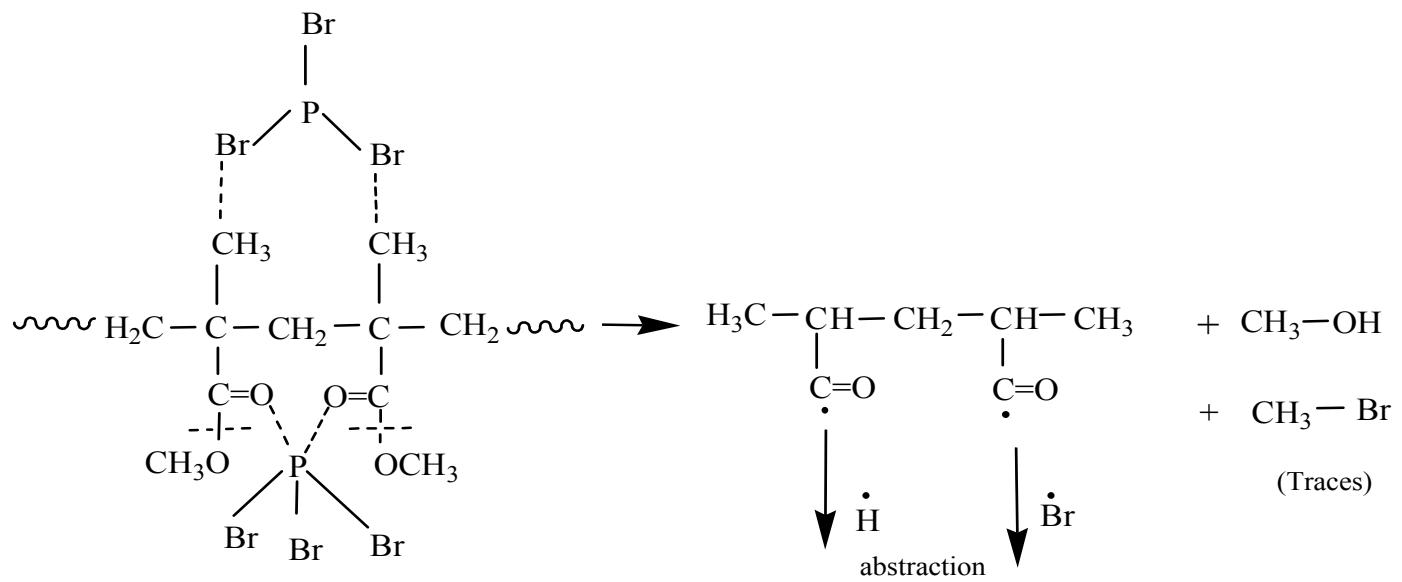

\section{Scheme III}

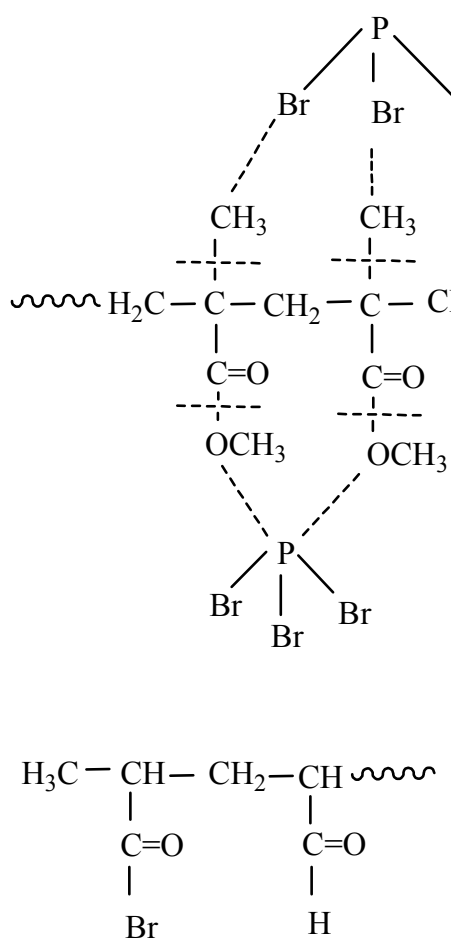

$\mathrm{Br}$<smiles>CC(C=O)CC(C)C(=O)Br</smiles> 


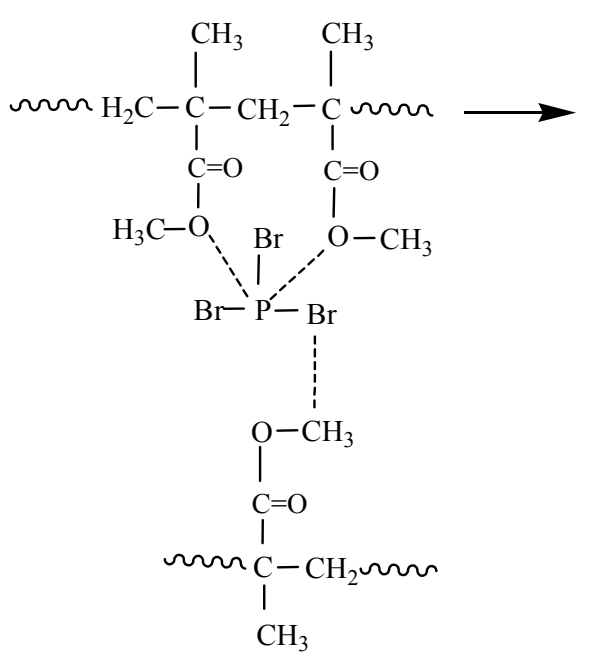<smiles>CC(C)C(=O)OP1OC(=O)C(C)CC(C)C(=O)O1</smiles>

Scheme V<smiles>COC(=O)C(C)(CC(C)(I)I)C(=O)OC</smiles><smiles>COC(=O)C(C)(C)CC(C)(Br)C(=O)OC</smiles>

Scheme VI

Table 3. GC-MS results of blend, B4 after heating at $250^{\circ} \mathrm{C}, 300^{\circ} \mathrm{C}$ and $400^{\circ} \mathrm{C}$.

\begin{tabular}{|c|c|c|c|c|c|}
\hline \multicolumn{2}{|c|}{$\begin{array}{c}\text { Blend heated at } \\
250^{\circ} \mathrm{C}\end{array}$} & \multicolumn{2}{|c|}{$\begin{array}{c}\text { Blend heated at } \\
300^{\circ} \mathrm{C} \\
\end{array}$} & \multicolumn{2}{|r|}{$\begin{array}{c}\text { Blend heated at } \\
400^{\circ} \mathrm{C} \\
\end{array}$} \\
\hline $\begin{array}{c}\text { Peak } \\
\text { no. }\end{array}$ & Product identified & $\begin{array}{c}\text { Peak } \\
\text { no. }\end{array}$ & Product identified & $\begin{array}{c}\text { Peak } \\
\text { no. }\end{array}$ & Product identified \\
\hline 1 & $\begin{array}{c}\mathrm{C}_{2} \mathrm{H}_{3} \mathrm{O}_{2} \mathrm{Br}, \mathrm{C}_{3} \mathrm{H}_{6} \mathrm{O} \\
\mathrm{CH}_{4} \mathrm{O}\end{array}$ & 1 & $\mathrm{C}_{2} \mathrm{H}_{3} \mathrm{OBr}$ & 1 & $\mathrm{C}_{5} \mathrm{H}_{9} \mathrm{Br}$ \\
\hline 2 & $\mathrm{C}_{5} \mathrm{H}_{11} \mathrm{O}_{2} \mathrm{P}$ & 2 & $\mathrm{C}_{2} \mathrm{H}_{4} \mathrm{OPBr}$ & 2 & $\mathrm{C}_{2} \mathrm{H}_{4} \mathrm{PBr}$ or $\quad \mathrm{CH}_{2} \mathrm{OPBr}$ \\
\hline 3 & $\mathrm{C}_{3} \mathrm{H}_{8} \mathrm{PBr}$ & 3 & $\mathrm{CH}_{3} \mathrm{OBr}$ & 3 & $\mathrm{C}_{7} \mathrm{H}_{14} \mathrm{O}_{3} \mathrm{P}_{2}, \mathrm{C}_{8} \mathrm{H}_{13} \mathrm{O}_{4} \mathrm{P}$ \\
\hline 4 & $\mathrm{C}_{4} \mathrm{H}_{9} \mathrm{Br}$ & 4 & $\mathrm{C}_{6} \mathrm{H}_{12} \mathrm{PBr}$ & 4 & $\mathrm{C}_{7} \mathrm{H}_{11} \mathrm{O}_{2} \mathrm{Br}$ \\
\hline 5 & Unidentified & 5 & $\mathrm{C}_{11} \mathrm{H}_{17} \mathrm{O}_{6} \mathrm{P}$ & 5 & $\mathrm{C}_{8} \mathrm{H}_{11} \mathrm{O}_{2} \mathrm{PBr}$ \\
\hline 6 & Unidentified & 6 & $\mathrm{C}_{10} \mathrm{H}_{17} \mathrm{O}_{4} \mathrm{Br}$ & 6 & $\mathrm{C}_{12} \mathrm{H}_{21} \mathrm{O}_{3} \mathrm{P}_{2} \mathrm{Br}$ \\
\hline 7 & $\mathrm{C}_{4} \mathrm{H}_{5} \mathrm{O}_{2} \mathrm{Br}$ & -- & -- & -- & -- \\
\hline 8 & $\mathrm{C}_{4} \mathrm{H}_{7} \mathrm{Br}_{2}$ & -- & -- & -- & -- \\
\hline 9 & $\mathrm{C}_{9} \mathrm{H}_{14} \mathrm{O}_{3} \mathrm{PBr}$ & -- & -- & -- & -- \\
\hline
\end{tabular}

high temperature for short time. Modified MMA units were found confirming the products identified in different temperature zones earlier. Traces of MMA units were also detected which is in accordance with earlier findings. It is further concluded (peak 5) that parts of the pendent groups of MMA units are equally liable to replacement by bromine and phosphorus.

The interaction between additive and polymer is established. The GC-MS studies help in understanding the mechanism of degradation of the blended system. This interaction imparts stability to the system in certain regions (TG curves). The orientation of $\mathrm{PBr}_{3}$ in the system appears to have profound impact on the formation of the products identified during degradation at different temperatures. The cross-linking of adjacent chains by the presence of phosphorus gives stability to the system. In addition to this, phosphorus and bromine when terminate the degrading polymer also play role in the formation of these products which 'block' further degradation in the regions of stability.

\subsection{Flammability Behaviour of Neat Polymer and its Blends}

Horizontal burning rate (HBR) and time to burn neat 


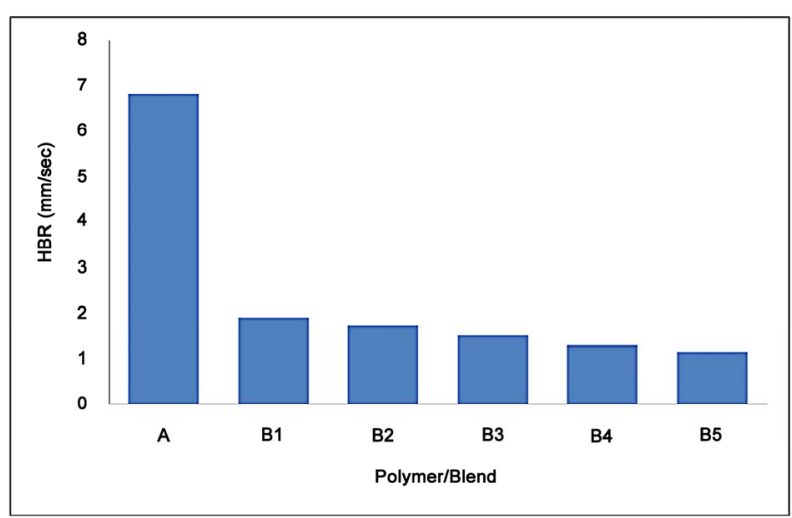

Figure 12. Horizontal burning rate of polymer and its blends.

Table 4. Horizontal burning rate (HBR) for polymer (A) and blends, B1-B4.

\begin{tabular}{ccccccc}
\hline $\begin{array}{c}\text { Polymer/Blend } \\
\text { code number }\end{array}$ & A & B1 & B2 & B3 & B4 & B5 \\
\hline $\begin{array}{c}\text { Time to burn } \\
(\mathrm{sec})\end{array}$ & 11 & 39 & 43 & 49 & 58 & 65 \\
\hline $\begin{array}{c}\text { Length of strip } \\
(\mathrm{mm})\end{array}$ & 75 & 75 & 75 & 75 & 75 & 75 \\
\hline $\mathrm{HBR}(\mathrm{mm} / \mathrm{sec})$ & 6.8 & 1.9 & 1.7 & 1.5 & 1.29 & 1.15 \\
\hline $\mathrm{mm}=$ millimeter, sec $=$ second. & & & &
\end{tabular}

polymer and its blends are tabulated in Table 4. The trend is clearly a linear one (Figure 12). Higher the concentration of additive in the blend, lower is the rate of burning obtained. It has been observed that burning rate of blend (B5) decreases to 6 times compared to neat polymer (A). Reduction in burning rate is much more pronounced even with the lowest proportion of additive (B1) and this is easily explained by the retardency caused by the additive towards polymer's flammability. The uniform distribution of all concentrations of additive throughout polymer is also confirmed.

\section{CONCLUSIONS}

1) The blends (PMMA-PBr ${ }_{3}$ ) lose weight at lower temperatures than neat polymer.

2) Despite early destabilization, the blends exhibit stabilization temperature zones.

3) The interaction between the components appears to be purely chemical.

4) The earlier decomposition is attributed to the splitting of $\mathrm{PBr}_{3}$ releasing bromine free radicals $(\mathrm{Br})$.

5) The formation of products involving phosphorus as part of degrading polymer imparts stability to the blends.

6) The "engaging" of separate polymer chains by phosphorus is another reason of stabilization of the binary system.

7) It seems that free radicals (Br) not only start the early depolymerization of the polymer but also inhibits this process, thus, providing one more point for stabilization.

8) The pendent groups of polymer or a part of them are equally liable to replacement by phosphorus and bromine.

9) The production of monomer has decreased significantly furnishing ample evidence for chemical interaction between the constituents of the system.

\section{ACKNOWLEDGEMENTS}

The authors would like to express their gratitude to PINSTECH, Islamabad, Pakistan for providing the opportunity to undertake this research work. Messrs Nehad Ali (Senior Tech. IAD, PINSTECH), Nadeem Ahmad and Muhammad Adeel Khattak are acknowledged for drawing of figures and technical help.

\section{REFERENCES}

[1] Laachachi, A., Cochez, M., Ferriol, M., Leroy, E., Lopez, C.M. and Oget, N. (2004) Influence of $\mathrm{Sb}_{2} \mathrm{O}_{3}$ particles as filler on the thermal stability and flammability properties of poly (methyl methacrylate) (PMMA). Polymer Degradation and Stability, 85(1), 641-646.

[2] Ebdon, J.R., Hunt, B.J. and Joseph, P. (2004) Thermal degradation and flammability characteristics of some polystyrenes and poly (methyl methacrylate) chemically modified with silicon-containing groups. Polymer Degradation and Stability, 83(1), 181-185.

[3] Gentilhomme, A., Cochez, M., Ferriol, M., Oget, N. and Mieloszynski, J.L. (2003) Thermal degradation of methyl methacrylate polymers functionalized by phosphorus containing molecules - II: Initial flame retardance and mechanistic studies. Polymer Degradation and Stability, 82(2), 347-355

[4] Price, D., Pyrah, K., Hull, T.R., Milnes, G.J., Ebdon, J.R., Hunt, B.J. and Joseph P. (2002) Flame retardance of poly (methyl methacrylate) modified with phosphorus - containing compounds. Polymer Degradation and Stability, 77(2), 227-233.

[5] Price, D., Pyrah, K., Hull, T.R., Milnes, G.J., Ebdon, J.R., Hunt, B.J., Joseph, P. and Konkel, C.S. (2001) Flame retarding poly (methyl methacrylate) with phosphorous containing compounds: Comparison of an additive with a reactive approach. Polymer Degradation and Stability, 74(3), 441-447.

[6] Ebdon, J.R., Price, D., Hunt, B.J., Joseph, P., Gao, F., Milnes, G.J. and Cunliffe, L.K. (2000) Flame retardance in some polystyrene and poly (methyl methacrylate) with covalently bound phosphorus - containing groups: Initial screening experiments and some laser pyrolysis mechanistic studies. Polymer Degradation and Stability, 69(3), 267-277.

[7] Chang, T.C. and Wu, K.H. (1997) The effect of silicon and phosphorus on the thermo-oxidative degradation of poly (methyl methacrylate). Polymer Degradation and Stability, 57(4), 325-330.

[8] Nair, C.P.R., Clouet, G. and Guilbert, Y. (1989) Flame and thermal resistance of phosphorous - functionalized poly (methyl methacrylate) and polystyrene. Polymer 
Degradation and Stability, 26(4), 305-331.

[9] Chandrasiri, J.A. and Wilkie, C.A. (1994) Thermal degradation of poly (methyl methacrylate) in the presence of tin (IV) chloride and tetraphenyltin. Polymer Degradation and Stability, 45(1), 91-96.

[10] Chandrasiri, J.A., Roberts, D.E. and Wilkie, C.A. (1994) The effect of some transition metal chlorides on the thermal degradation of poly (methyl methacrylate): A study using TGA-FTIR spectrometry. Polymer Degradation and Stability, 45(1), 97-101.

[11] McNeill, I.C. and McGuiness, R.C. (1984) The effect of zinc bromide on the thermal degradation of poly (methyl methacrylate): Part I - Thermal analysis studies and general nature of the interaction. Polymer Degradation and Stability, 9(3), 167-183.

[12] McNeill, I.C. and McGuiness, R.C. (1984) The effect of zinc bromide on the thermal degradation of poly (methyl methacrylate): Part 2 - Reaction products, structural changes and degradation mechanism. Polymer Degradation and Stability, 9(4), 209-224.

[13] Song, J., Fischer, C. H. and Schnabel, W. (1992) Thermal oxidative degradation of poly (methyl methacrylate). Polymer Degradation and Stability, 36(3), 261-266.

[14] Wochnowski, C., Eldin, M. A. S. and Metev S. (2005) UV-laser-assisted degradation of poly (methyl methacrylate). Polymer Degradation and Stability, 89(2), 252-264.

[15] Zulfiqar, S., Paracha, A. and Masud, K. (1996) The thermal degradation of poly (allyl methacrylate). Polymer Degradation and Stability, 52(1), 89-93.

[16] Zulfiqar, S., Masud, K., Siddique, B. and Paracha, A. (1996) Thermal degradation of phenyl methacrylate-styrene copolymers. Polymer Degradation and Stability, 52(3), 293-299.

[17] Zulfiqar, S., Masud, K., Piracha, A. and McNeill, I.C. (1997) Thermal degradation of allyl methacrylate-methyl methacrylate copolymers. Polymer Degradation and Stability, 55(3), 257-263.

[18] Zulfiqar, S. and Masud, K. (2000) Thermal degradation of blends of allyl methacrylate-methyl methacrylate copolymers with aluminum ethoxide. Polymer Degradation and Stability, 70(2), 229-236.

[19] Zulfiqar, S., Masud, K. and Ameer, Q. (2002) Thermal degradation of blends of phenyl methacrylate-styrene copolymers with aluminum ethoxide. Polymer Degradation and Stability, 77(3), 457-464.

[20] Zulfiqar, S. and Masud, K. (2002) Thermal degradation of blends of allyl methacrylate-methyl methacrylate copolymers with aluminum isopropoxide. Polymer Degradation and Stability, 78(2), 305-313.
[21] Zulfiqar, S., Masud, K. and Ameer, Q. (2003) Thermal degradation behavior of blends of phenyl methacrylate-styrene copolymers with aluminum isopropoxide. Journal of Thermal Analysis and Calorimetry, 73(3), 877-886.

[22] Arshad, M., Masud, K., Arif, M., Rehman, S., Chohan, Z.H., Arif, M., Qureshi, A.H., Saeed, A., Salma, U. and Awan, M.S. (2008) A comparative study of roles played by aluminum tribromide and aluminum acetylacetonate on the thermal degradation of PMMA by simultaneous thermoanalytical techniques. The Nucleus, 45(1-2), 63-72.

[23] Arshad, M., Masud, K., Arif, M., Rehman, S., Arif, M., Zaidi, J.H., Chohan, Z.H., Saeed, A. and Qureshi, A.H. (2009) The effect of $\mathrm{AlBr}_{3}$ additive on the thermal degradation of PMMA: A study using TG-DTA-DTG, IR and Py-GC-MS techniques. Journal of Thermal Analysis and Calorimetry, 96(3), 873-881.

[24] Riddick, J.A., Bunger, W.B. and Sakano, T.K. (1986) Organic solvents - physical properties and methods of purification. John-Wiley and Sons, New York.

[25] Furniss, B.S. and Vogel, A.I. (1978) Vogel's textbook of practical organic chemistry. Longman Group, London, 458-459.

[26] Grassie, N., McNeill, I.C. and Cooke, I. (1968) Thermal degradation of polymer mixtures. I. Degradation of polystyrene-poly (methyl methacrylate) mixtures and a comparison with the degradation of styrene-methyl methacrylate copolymers. Journal of Applied Polymer Science, 12, 831-837.

[27] Horowitz, H. H. and Metzger, G. A. (1963) New analysis of thermogravimetric traces. Analytical Chemistry, 35, 1464-1468.

[28] Flammability Test. UL94, ASTM D 635.

[29] Sain, M., Park, S.H., Suhara, F. and Law, S. (2004) Flame retardant and mechanical properties of natural fibre-PP composites containing magnesium hydroxide. Polymer Degradation and Stability, 83(2), 363-367.

[30] Smith, A.L. (1979) Applied infrared spectroscopy fundamentals, techniques and analytical problem-solving. John Wiley and Sons, A Wiley-Interscience Publication, New York, 297\&308.

[31] Sadtler Research Laboratories (1974) The Sadtler Standard Spectra. PA 5, Philadelphia.

[32] Robinson, J.W. (1974) CRC Handbook of spectroscopy. CRC Press, Inc., USA, 2.

[33] Szymanski, H.A. and Erikson, R. E. (1970) Infrared band handbook. 2nd Edition, IFI/Plenum, New York, 1-2. 